\title{
Construction Trades Workers
}

National Cancer Institute

\section{Source}

National Cancer Institute. Construction Trades Workers. NCI Thesaurus. Code C122436.

A tradesman, laborer (an unskilled tradesman), or professional employed in the physical construction of the built environment and its infrastructure. 